\title{
Combined suicide and cytokine gene therapy for peritoneal carcinomatosis
}

\author{
C Lechanteur, P Delvenne, F Princen, M Lopez, G Fillet, J Gielen, M-P Merville, V Bours
}

\begin{abstract}
Background-Gene therapy is a novel approach for the treatment of cancers, and tumours disseminated in the peritoneal cavity are suitable for in situ delivery of a therapeutic gene.

Aims-The efficacy of a therapy combining a suicide gene (herpes simplex virus type I thymidine kinase (HSV-TK)) and cytokine genes was investigated in a model of peritoneal carcinomatosis induced by colon carcinoma cells in syngeneic rats.

Material and methods-Pre-established macroscopic tumours in BDIX rats were treated by intraperitoneal injections of retrovirus producing cells (FLYA13 TK, FLYA13 granulocyte macrophage-colony stimulating factor (GM-CSF), FLYA13 interleukin 12 (IL-12)) and ganciclovir (GCV).
\end{abstract}

Results-TK/GCV treated animals showed a slight increase in survival time ( 72 days) compared with the control group (63 days) while the association of cytokine and TK/GCV gene therapy resulted in significantly improved survival, with a large proportion of animals remaining tumour free on day $480(60 \%$ and $40 \%$ for TK/GCVI GM-CSF and TK/GCV/IL-12 treated animals, respectively). Histological analysis of treated animals showed that the remaining tumour nodes were infiltrated by mononuclear cells but no major differences were observed between the various treatments. Immunohistochemical analysis revealed that lymphoid $\mathrm{CD}^{+}$and $\mathrm{CD}^{+}$ $T$ cells as well as macrophages accumulated outside untreated tumour nodes while $\mathrm{CD8}^{+}$and $\mathrm{CD}^{+} 5^{+}$activated $\mathrm{T}$ cells and macrophages heavily infiltrated the tumours after the different treatments.

Conclusions-Our data indicate that combined suicide and cytokine gene therapy is a powerful approach for the treatment of macroscopic peritoneal carcinomatosis. (Gut 2000;47:343-348)

Keywords: gene therapy; thymidine kinase; interleukin 12; granulocyte macrophage-colony stimulating factor; peritoneal carcinomatosis

Pathology, University of Liège, 4000 Liège, Belgium

P Delvenne

Correspondence to:

V Bours, Medical Oncology,

CHU B35, University of

Liège, Sart-Tilman

4000 Liège, Belgium. Email:

vbours@ulg.ac.be

Accepted for publication 4 April 2000

Suicide gene therapy is based on the intracellular delivery of a gene coding for an enzyme that transforms a prodrug into a cytotoxic product. ${ }^{12}$ A widely used suicide gene codes for the herpes simplex virus type I thymidine kinase (HSV-TK) which phosphorylates nucleoside analogues such as ganciclovir (GCV) to monophosphate metabolites. Further phos- phorylation by endogenous kinases leads to formation of cytotoxic ganciclovir triphosphate.

We previously demonstrated the efficacy of HSV-TK mediated gene therapy for peritoneal carcinomatosis induced by colorectal adenocarcinoma cells in a syngeneic immunocompetent animal model. ${ }^{34}$ Other investigators have explored the in vivo antitumour activity of the TK gene ${ }^{5-10}$ as well as its therapeutic effect in clinical trials. ${ }^{11}$ However, its efficacy is limited by its low in vivo transduction efficiency. Two approaches can be considered to improve the therapeutic efficacy of a suicide gene. Firstly, new vectors are being developed to increase the efficiency of gene delivery. Secondly, as only a small number of cells are transduced, the bystander effect, a mechanism allowing the killing of untransduced adjacent cells, is crucial and novel strategies are designed to render it more efficient.

Interestingly, a strong bystander effect was observed in our animal model ${ }^{3}$ and in other experimental systems. ${ }^{6}{ }^{12}$ Several mechanisms have been proposed to explain this effect, such as the transfer of apoptotic vesicles between adjacent cells or metabolic cooperation through gap junctions. However, several studies have indicated that in vivo, immunity plays an important role in the bystander effect after TK/GCV gene therapy. ${ }^{14}$

The aim of our study was to boost the bystander effect to achieve longlasting survival and tumour eradication in our model by combined cytokine and TK/GCV gene therapy. Interleukin 12 (IL-12) (5-21 $^{15}$ and granulocyte macrophage-colony stimulating factor $(\mathrm{GM}-\mathrm{CSF})^{22-25}$ are two cytokines that have been used successfully in immunotherapy in different models of established tumours. We chose to use retroviral vectors as such vectors were previously demonstrated to be efficient in our model. Moreover, adenoviral vectors can lead to important inflammatory reactions that could be deleterious in a strategy with repeated injections of vectors delivering cytokine genes. Our results demonstrated that the association of IL-12 or GM-CSF in situ expression with retroviral HSV-TK gene therapy and GCV treatment significantly improved survival rates and the proportion of tumour free survivors.
Abbreviations used in this paper: TK, thymidine kinase; HSV, herpes simplex virus; IL-12, interleukin 12; GM-CSF, granulocyte macrophage-colony stimulating factor; GCV, ganciclovir; HBSS, Hanks' balanced salt solution; PCR, polymerase chain reaction; PBS, phosphate buffered saline; BSA, bovine serum albumin; APC, antigen presenting cells; pfu, plaque forming units. 


\section{Methods}

ANIMALS, VECTORS, AND CELL LINES

Eight week old syngeneic BDIX rats were purchased from Iffa-Credo (l'Arbresle, France). DHD/K12 Prob cells, FLYA13 packaging cells, and HSV-TK and BAG retroviral vectors have been described previously. ${ }^{34}$

In the GM-CSF and IL-12 retroviral vectors (MoMuLV), murine GM-CSF or IL-12 p40 and $p 35$ genes were placed under the control of the first long terminal repeat and the neomycin resistance gene was driven by an SV-40 promoter. To achieve balanced expression of both the p40 and p35 subunits of mIL-12, we used a bicistronic vector that contains an internal ribosome entry site derived from the encephalomyocarditis virus.

GM-CSF and IL-12 coding sequences were amplified by polymerase chain reaction (PCR) from the pcDNA1 GM-CSF or IL-12 plasmids using Bam HI primers, and PCR products (500 bp) were inserted at the Bam HI site of the BAG retroviral vector instead of the lac $Z$ gene. The pcDNA1 GM-CSF and pcDNA1 IL-12 expression vectors were generous gifts from Professor K Thielemans (Laboratory of Haematology and Immunology, VUB, Brussels, Belgium).

The integrity of the GM-CSF and IL-12 p40 and p35 DNA sequences was confirmed by DNA sequencing.

IL-12 and GM-CSF retroviral vectors were transfected in the FLYA13 packaging cell line by lipofection (DOTAP, Boehringer Mannheim, Germany). Colonies were isolated by G418 selection (geneticin: active concentration $0.5 \mathrm{mg} / \mathrm{ml}$ ) and expanded.

\section{CYTOKINE ASSAYS}

Secretion of IL-12 and GM-CSF by liposome transfected packaging cells was determined using the Quantiquine ELISA kit (R\&D Systems, Wiesbaden, Germany) for detection of murine GM-CSF and the Intertest-12x ELISA kit (Genzyme, Cambridge, Massachusetts, USA) for quantification of mouse IL-12 p70. Briefly, $10^{6}$ transduced cells were plated in $25 \mathrm{~cm}^{2} \mathrm{~T}$ flasks with $5 \mathrm{ml}$ of culture medium supplemented with G418 (0.5 mg/ml). Forty eight hours later supernatants were centrifuged and tested for mIL-12 or mGM-CSF production by ELISA. Results were expressed in $\mathrm{ng} / 10^{6}$ cells $/ 48$ hours.

\section{IN VIVO TRANSDUCTION}

BDIX rats were injected intraperitoneally on day 0 with $10^{6} \mathrm{DHD} / \mathrm{K} 12$ live parental tumour cells. On days 7,14 , and 21 , the animals received three intraperitoneal injections of $30 \times 10^{6}$ retrovirus producing FLYA13-TK cells per animal with or without $20 \times 10^{6}$ cells producing GM-CSF or IL-12 retroviruses (FLYA13 GM-CSF or FLYA13 IL-12). They were treated with either GCV (150 mg/kg/day) diluted in Hanks' balanced salt solution (HBSS, Life Technologies, Gaithersburg, Maryland, USA) from days 10-13, 17-20, and 24-27 or with HBSS buffer alone according to the same schedule.
HISTOLOGICAL ANALYSIS AND

IMMUNOHISTOCHEMICAL STUDIES

Samples of tumours on visceral peritoneum were excised, snap frozen on dry ice using Tissue-Tek and stored at $-70^{\circ} \mathrm{C}$. Sections $(5 \mu \mathrm{m})$ were obtained with a cryostat, fixed with carbowax, and stained with haematoxylineosin for histological analysis or fixed with cold acetone for 10 minutes and immunostained with specific antibodies for detection of infiltrating cells using the peroxidase method. For this purpose, sections were incubated for 15 minutes in phosphate buffered saline (PBS) $/ 1 \%$ bovine serum albumin (BSA) and then overnight at $4^{\circ} \mathrm{C}$ with monoclonal antibodies diluted in PBS $/ 1 \%$ BSA. We used the following antibodies: antimacrophages (ED1, 1/500), anti-CD8 (MRC OX8, 1/100), antiCD4 (MRC OX35, 1/500), anti-CD25 (MRC OX39, 1/100), and anti-NK/LAK cells (3.2.3., $1 / 50)$. These are specific mouse monoclonal
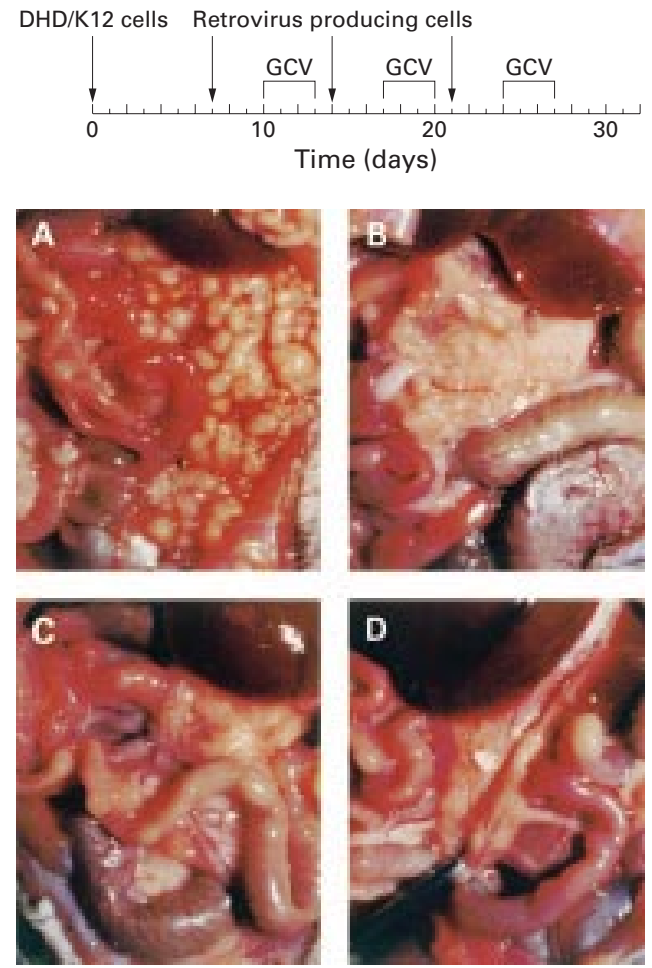

Figure 1 Tumour response after gene therapy with thymidine kinase/ganciclovir (TK/GCV) plus cytokines. Rats injected with $\mathrm{DHD} / \mathrm{K} 12$ cells received three intraperitoneal injections of herpes simplex virus type I thymidine kinase (HSV-TK) retrovirus producing FLYA13 TK cells together with cytokine retrovirus producing FLYA13 granulocyte macrophage-colony stimulating factor (GM-CSF) or FLYA13 interleukin 12 (IL-12) cells. Each injection was followed by treatment with GCV or Hanks'balanced salt solution (HBSS). (Top)

Protocol for intraperitoneal delivery of retrovirus producing cells and GCV treatment. Each group (six animals/group) was injected intraperitoneally with $10^{6} \mathrm{DHD} / \mathrm{K} 12$ cells on day 0. The HSV-TK, GM-CSF, and IL-12 producing cells FLYA13 TK, FLYA13 GM-CSF, and FLYA13 IL-12 were injected intraperitoneally on days 7, 14, and 21. For the GCV treated groups, the first treatment was administered from days 10-13, the second from days 17-20, and the third from days 24-27. Treatment comprised $150 \mathrm{mg} / \mathrm{kg}$ of GCV once a day. At the same time, the control group received $10 \mathrm{ml}$ of HBSS once daily. (Bottom) Animals were killed on day 30 and a representative picture of the peritoneal cavity is shown: $(A)$ control rat, $(B)$ rat treated with $T K / G C V,(C)$ rat treated with $T K / G C V / I L-12$, and $(D)$ rat treated with TK/GCV/GM-CSF. 


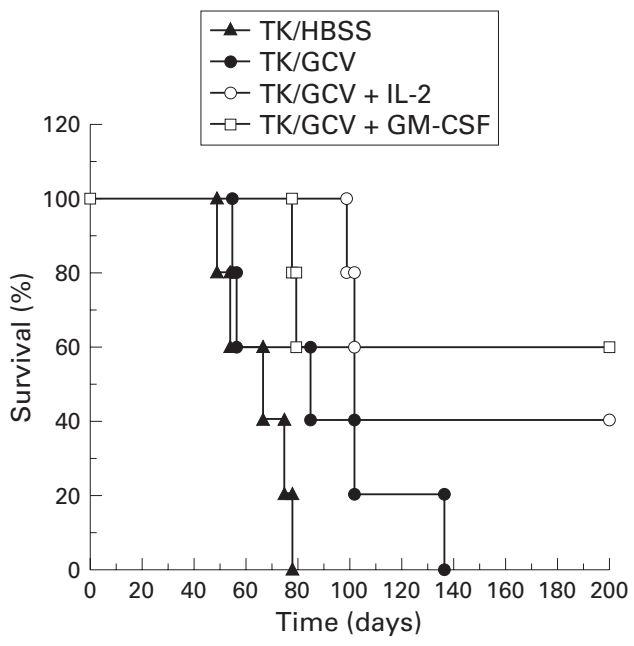

Figure 2 Survival of rats treated with thymidine kinase/ganciclovir (TK/GCV) and cytokine genes. Five animals from each group were monitored until they died. In the group who received herpes simplex virus type I thymidine kinase (HSV-TK) and granulocyte macrophage-colony stimulating factor (GM-CSF) producing FLYA13 cells, three of five animals were still alive and tumour free on day 480 while two of five animals were still alive at the same time in the HSV-TK/interleukin 12 (IL-12) group. HBSS, Hanks'balanced salt solution.

antirat antibodies and were purchased from Serotec (Oxford, UK). After washing in PBS, slides were stained with a peroxidase conjugated goat antimouse IgG antibody (Serotec) $1 / 50$ in $\mathrm{PBS} / 1 \% \mathrm{BSA}$ for 30 minutes at room temperature, washed, and positive cells visualised using diaminobenzidine as the chromogen.

STATISTICS

Kaplan-Meyer curves were established for each group and survival rates were compared using the log rank test.

\section{Results}

RETROVIRUS PRODUCING CELL LINES AND CYTOKINE EXPRESSION

In this study we used the FLYA13 packaging cell line which is known to produce high titres of retroviruses resistant to inactivation by human serum. ${ }^{26}$ In previous studies we generated an HSV-TK retrovirus producing cell line (FLYA13 TK). ${ }^{4}$ Two other cell lines were generated (FLYA13 IL-12 and FLYA13 GMCSF) by transfection of a retroviral vector (MoMuLV-derived) containing IL-12 p40 and p35 or GM-CSF cDNAs, respectively. After G418 selection, we measured the number of retroviral particles produced by the different cell lines and reproducibly found a titre of $2 \times 10^{5}$ plaque forming units (pfu)/ml for FLYA13 TK cells, $10^{4} \mathrm{pfu} / \mathrm{ml}$ for FLYA13 IL-12 cells, and $10^{5} \mathrm{pfu} / \mathrm{ml}$ for FLYA13 GM-CSF cells.

The FLYA13 IL-12 and FLYA13 GM-CSF retrovirus producing cell lines were also analysed for cytokine expression. FLYA13 IL-12 cells produced $60 \mathrm{ng}$ of IL-12/10 cells/48 hours and FLYA13 GM-CSF cells $30 \mathrm{ng}$ of GM-CSF $/ 10^{6}$ cells $/ 48$ hours (data not shown).
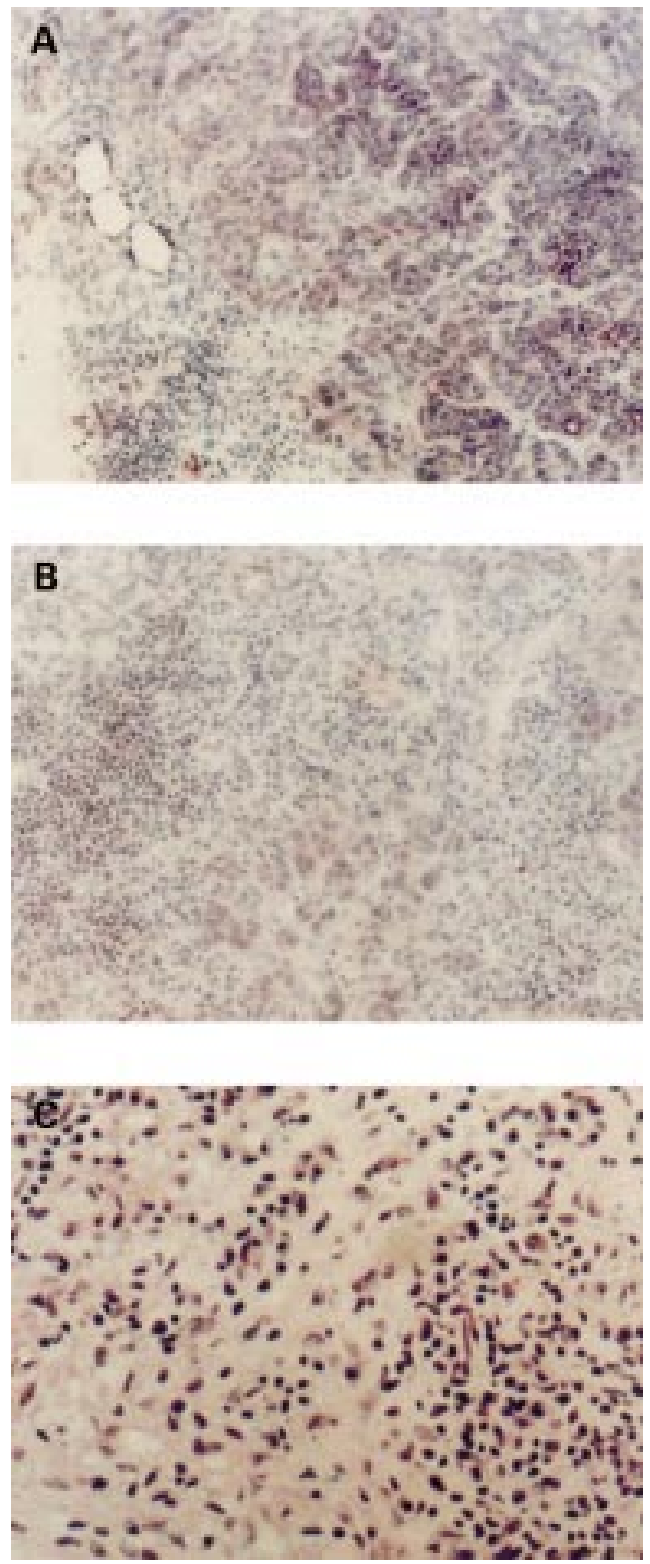

Figure 3 Standard histology of the tumours.

Haematoxylin-eosin staining of intraperitoneal tumours from $(A)$ control $(100 \times$ magnification) or $(B, C)$ treated animals (100x and 200x magnification, respectively).

TREATMENT OF RATS BEARING ESTABLISHED TUMOURS

We investigated the efficiency of HSV-TK gene therapy combined with cytokine gene therapy in a model of peritoneal carcinomatosis induced by DHD/K12 colorectal adenocarcinoma cells in syngeneic BDIX rats. BDIX rats were injected intraperitoneally on day 0 with $10^{6} \mathrm{DHD} / \mathrm{K} 12$ cells and received three intraperitoneal injections of retrovirus producing FLYA13 TK cells on days 7, 14, and 21 with or without FLYA13 IL-12 or FLYA13 GM-CSF cells. Rats were treated with GCV $(150 \mathrm{mg} / \mathrm{kg} /$ day) from days 10-13, 17-20, and 24-27. Control animals were injected with FLYA13 TK cells and treated with HBSS buffer alone according to the same schedule as the GCV treated group (fig 1A).

At the end of the protocol (day 30), one animal from each group was killed and peritoneal 
dissemination of the tumour was assessed by direct abdominal examination (fig 1B). The peritoneal cavity of the control animal was
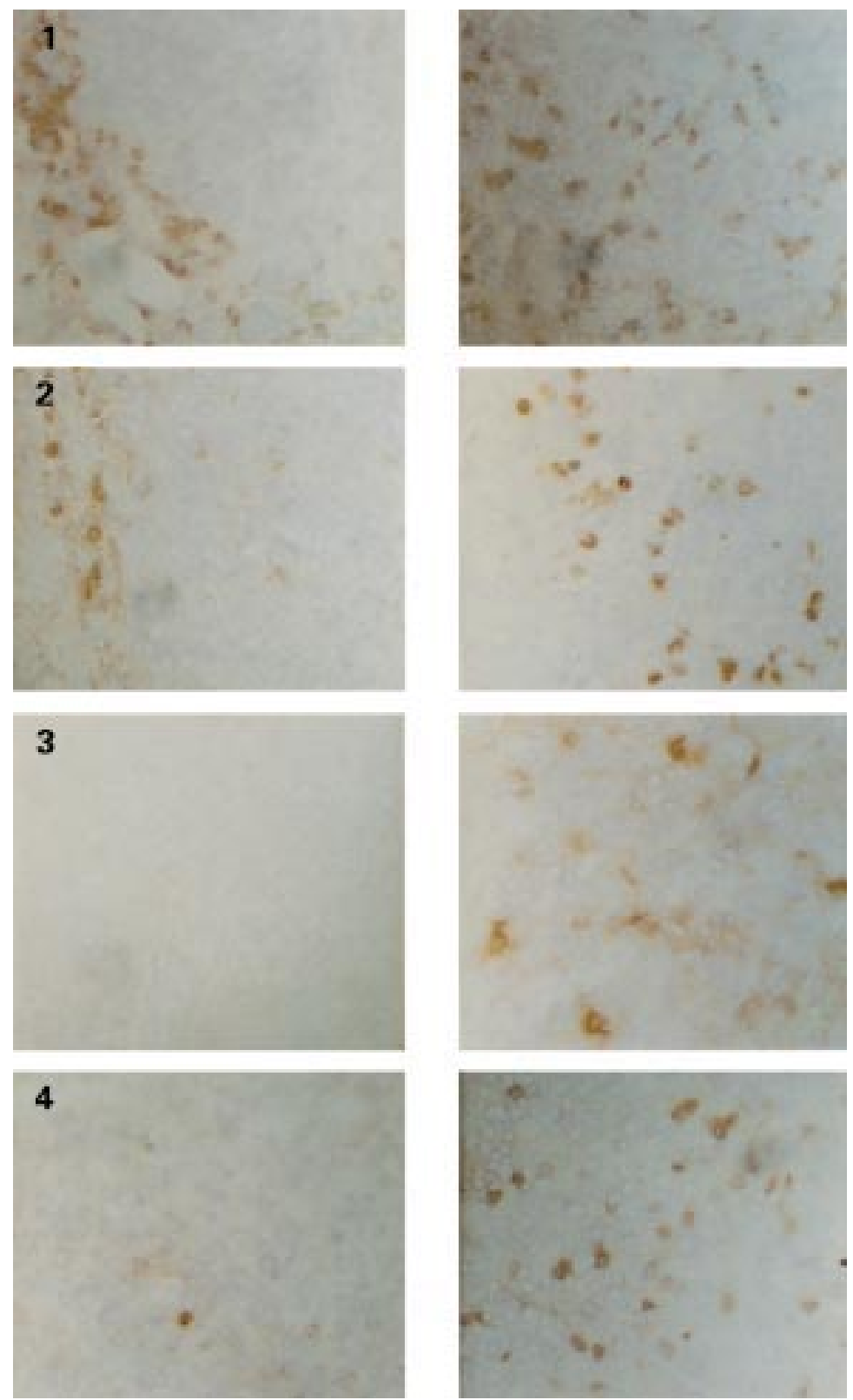

Figure 4 Immunohistochemical staining using anti-CD8 $8^{+}$(1), antimacrophage (2), anti-CD25+ (3), or anti-NK cell (4) antibodies on frozen sections of tumours from control (left) or treated (right) animals (250× magnification).

Table 1 Immunostaining of lymphoid and macrophagic cells infiltrating the tumours after thymidine kinase/ganciclovir (TK/GCV) or combined TK/GCV/interleukin 12 (IL-12) or TK/GCV/granulocyte macrophage-colony stimulating factor (GM-CSF) treatments. Shown are the average scores after immunostaining with the different antibodies (arbitrary scale graded from - to +++ ). In each case, control untreated animals were compared with animals that had received one (day 14), two (day 21), or three (day 27) courses of retrovirus producing cells plus GCV. In treated animals, few biopsies showed any residual tumours and the proportion of tumour free biopsies for each condition is indicated in the first column. Results are given separately for the tumour $(T)$ itself and the stroma $(S)$ corresponding to the corona of inflammatory cells surrounding the tumour

\begin{tabular}{|c|c|c|c|c|c|c|c|}
\hline & \multirow{2}{*}{$\begin{array}{l}\text { Tumour free } \\
\text { samples }\end{array}$} & \multicolumn{2}{|c|}{$C D 8$} & \multicolumn{2}{|c|}{$C D 25$} & \multicolumn{2}{|l|}{ ED1 } \\
\hline & & $T$ & $S$ & $T$ & $S$ & $T$ & $S$ \\
\hline Controls & $0 \%$ & - & + & - & - & + & + \\
\hline HSV-TK/GCV & $55 \%$ & ++ & +++ & - & + & + & +++ \\
\hline HSV-TK/GCV+IL-12 & $83 \%$ & ++ & +++ & + & + & +++ & +++ \\
\hline HSV-TK/GCV+GM-CSF & $20 \%$ & ++ & +++ & + & + & + & ++ \\
\hline
\end{tabular}

completely invaded by tumour nodes (fig 1A) while the TK/GCV treated animal showed a highly reduced tumour burden (fig $1 \mathrm{~B}$ ). Combined therapies (TK/GCV/IL-12 (fig $1 \mathrm{C}$ ) or $\mathrm{TK} / \mathrm{GCV} / \mathrm{GM}-\mathrm{CSF}$ (fig 1D)) resulted in further tumour regression with virtually no visible tumour.

Five animals from each group were monitored and survival curves were established. Control HBSS treated animals died between days 48 and 77 (median survival 63 days) while rats injected with the FLYA13 TK retrovirus producing cells and treated with GCV died between days 54 and 136 (median survival 72 days), thus showing an increased survival time (fig 2). In this experiment, the survival difference failed to reach significance (log rank test $\mathrm{p}=0.1$ ).

However, the combination of cytokine gene therapy and HSV-TK/GCV gene therapy resulted in significantly improved survival rates $(\log$ rank test $\mathrm{p}<0.05)$ with a large proportion of animals remaining tumour free. Indeed, $60 \%$ of animals treated with FLYA13 TK/ GCV in combination with FLYA13 GM-CSF and $40 \%$ of animals treated with FLYA13 TK/GCV and FLYA13 IL-12 were still alive on day 480 (fig 2).

HISTOLOGICAL ANALYSIS AND IMMUNOHISTOCHEMICAL STUDIES

Standard histology of untreated tumours has been described previously. ${ }^{27}$ Briefly, haematoxylin-eosin stained sections of the tumour tissues, harvested on days 14, 21, and 27 , revealed sheets or nodules of poorly differentiated epithelial cells surrounded by a fibrous stroma with a focally extensive desmoplastic reaction. Mononuclear cells with scattered eosinophilic granulocytes were also found interspersed between the tumour nodules (fig $3 \mathrm{~A})$. In treated rats, the main difference was replacement of some or, in some cases, all cancer nodules by an extensive mononuclear cell infiltrate. These inflammatory cells were observed around necrotic or tumour areas but were also found to infiltrate these areas (fig 3B). No major changes in these histological features were observed between the different treatments.

Immunohistological analysis of untreated tumours showed that lymphoid $\mathrm{CD}^{+}$and $\mathrm{CD}^{+} \mathrm{T}$ cells as well as macrophages accumulated outside the tumour nodes (fig 4, table 1). After TK/GCV gene therapy, the tumours were heavily infiltrated by $\mathrm{CD}^{+}$cytotoxic $\mathrm{T}$ cells and macrophages (fig 4, table 1). We did not observe any significant difference after treatment with TK/GCV in combination with IL-12 or GM-CSF compared with TK/GCV alone regarding $\mathrm{CD}^{+} \mathrm{T}$ cell or macrophage infiltration. However, the number of $\mathrm{CD} 25^{+}$ activated $\mathrm{T}$ cells infiltrating the tumour was higher after combined therapies (table 1).

\section{Discussion}

Peritoneal carcinomatosis remains a major clinical problem as neither surgery nor chemotherapy can eradicate these tumours. Thus 
novel therapeutic approaches are required to treat these cancers which may constitute a suitable model for gene therapy.

We previously demonstrated that three injections of retrovirus producing FLYA13 TK cells followed by GCV treatment significantly increased the survival rate of rats bearing extensive $\mathrm{DHD} / \mathrm{K} 12$ derived peritoneal carcinomatosis. ${ }^{4}$ Nevertheless, very few treated animals remained tumour free $(10 \%)$, confirming that the TK gene alone rarely eradicates established solid tumours. ${ }^{46}$

One way of improving HSV-TK gene therapy is to boost the bystander effect. Several studies have reported that the immune system participates in the bystander effect following TK/GCV gene therapy. ${ }^{28-33}$ For example, several groups highlighted the failure of immunodeficient or sublethally irradiated mice to reject HSV-TK transfected tumours after GCV treatment, indicating that the bystander effect relies in part on an intact immune system. ${ }^{32} 33$ Therefore, if HSV-TK/GCV treatment depends on the development of an antitumour immune response to achieve long term remission, its success should be improved by concomitant stimulation of the immune system. As antigens are released after HSV-TK GCV gene therapy, simultaneous local expression of appropriate cytokines could initiate such an effect. ${ }^{34}{ }^{35}$ Indeed, a few studies have demonstrated that the efficacy of TK/GCV gene therapy is improved by simultaneous administration of the IL-2 gene or by a combination of the IL-2 and GM-CSF genes. ${ }^{36-38}$

In the present study, when FLYA13 IL-12 or FLYA13 GM-CSF cells were combined with FLYA13 TK cells, a highly significant increase in survival was observed. Moreover, $60 \%$ and $40 \%$ of TK/GM-CSF and TK/IL-12 treated rats, respectively, were apparently free of tumour on day 480 and could be considered as cured.

HSV-TK/GCV gene therapy leads to necrosis in several tumour models. ${ }^{30} 33$ Tumour antigens are thus available to the immune system and may activate an antitumour immune response through uptake and presentation by antigen presenting cells (APC). GM-CSF is known to induce APC differentiation and may promote maturation of APC previously attracted to the tumour site by TK/GCV treatment, rendering them more effective.

In contrast, several groups have previously described a Th1 immune response after HSVTK/GCV therapies in different models. ${ }^{29}$ IL-12 is a proinflammatory cytokine which enhances $\mathrm{CD}^{+} \mathrm{T}$ cell cytolytic activity and supports the differentiation of Th 1 helper $\mathrm{CD} 4^{+} \mathrm{T}$ cells. In situ production of IL-12 may enhance this Th1 immune response pathway, generating cytotoxic $\mathrm{CD}^{+} \mathrm{T}$ cells.

Indeed, co-expression of GM-CSF or IL-12 with the TK gene led to improved survival in our model, suggesting that a better antigen presentation or a more efficient Th 1 response could improve TK therapeutic activity. Tumour infiltration by $\mathrm{CD}^{+} \mathrm{T}$ cells and macrophages after TK/GCV gene therapy confirms that such a treatment induces an immune response, as previously suggested by several studies; however, we did not observe significant differences in the immune infiltrates generated by the three therapeutic strategies. But although the number of infiltrating lymphoid or macrophagic cells remained approximately equivalent, animals treated with cytokine genes in addition to TK/GCV probably developed a more effective antitumour immune response.

Our data confirm that an immune reaction is associated with TK/GCV gene therapy and indicate that a strategy combining a suicide gene and cytokine genes may be a way of improving the results of gene therapy. Interestingly, boosting the immune response may also have an effect on lesions away from the injected tumour, such as micrometastases. Indeed, several observations indicate that, under certain experimental conditions, suicide gene therapy can induce a systemic immune response, capable of mediating regression of distant metastases after eradication of a localised cytosine deaminase or thymidine kinase expressing tumour. ${ }^{39} 40$

In conclusion, our data confirm that suicide genes have only a limited efficacy and that their antitumour activity may be increased by simultaneous expression of cytokine genes. Clinical trials should be considered with combined therapies.

We thank Dr C-M. Calberg for the TK retroviral vector and Professor K Thielemans (VUB, Brussels, Belgium) for the GM-CSF and IL-12 genes. We thank L-M Dupuis and C Hauglustaine for technical assistance and J-P Cheramibien for excellent help with the animals. PD and M-PM are research associates and VB is a senior research associate at the National Fund for Scientific Research (Belgium). FP is supported by a FRIA fellowship. This research was supported by grants from "Centre Anti-Cancereux" (Liege, Belgium) and from the munauté Française de Belgique.

1 Freeman SM, Whartenby KA, Freeman JL, et al. In situ use of suicide genes for cancer therapy. Semin Oncol 1996;23:31-45.

2 Moolten FL, Wells JM, Heyman RA, et al. Lymphoma regression induced by ganciclovir in mice bearing a herpes thymidine kinase transgene. Hum Gene Ther 1990;1:12534 .

3 Lechanteur C, Princen F, Lo Bue S, et al. HSV-1 thymidine kinase gene therapy for colorectal adenocarcinoma-derived peritoneal carcinomatosis. Gene Ther 1997;4:1189-94.

4 Princen F, Lechanteur C, Lopez M, et al. Repeated cycles of retrovirus-mediated HSVtk gene transfer plus ganciclovir increase survival of rats with peritoneal carcinomatosis. Gene Ther 1998;5:1054-60.

5 Barba D, Hardin J, Ray J, et al. Thymidine kinase-mediated killing of rat brain tumors. $\mathcal{F}$ Neurosurg 1993;79:729-35.

6 Caruso M, Panis Y, Gagandeep S, et al. Regression of established macroscopic liver metastases after in situ transduction of a suicide gene. Proc Natl Acad Sci USA 1993;90:7024-8.

7 Culver KW, Ram Z, Walbridge S, et al. In vivo gene transfer with retroviral vector-producer cells for treatment of experimental brain tumors. Science 1992;256:1550-2.

8 Moolten FL, Wells JM. Curability of tumors bearing herpes thymidine kinase genes transferred by retroviral vectors. $\mathcal{f}$ Natl Cancer Inst 1990;82:297-300.

9 Maron A, Gustin T, Le Roux A, et al. Gene therapy of rat C6 glioma using adenovirus-mediated transfer of the herpes simplex virus thymidine kinase gene: long-term follow-up by magnetic resonance imaging. Gene Ther 1996; 3:315-22.

10 Ram Z, Culver KW, Walbridge S, et al. In situ retroviralmediated gene transfer for treatment of brain tumors in rats. Cancer Res 1993;53:83-8.

11 Sterman DH, Treat J, Litzky A, et al. Adenovirus-mediated herpes simplex virus thymidine kinase/ganciclovir gene therapy in patients with localized malignancy: results of a phase I clinical trial in malignant mesothelioma. Hum Gene Ther 1998;7:1083-92.

12 Chen C-Y, Chang Y-N, Ryan P, et al. Effect of herpes simplex virus thymidine kinase expression levels on panciclovir-mediated cytotoxicity and the "bystander effect". Hum Gene Ther 1995;6:1467-76.

13 Freeman SM, Abboud CN, Whartenby KA, et al. The "bystander-effect": tumor regression when a fraction of the tumor mass is genetically modified. Cancer Res 1993;53: tumor mass 
14 Freeman SM, Ramesh R, Marrogi AJ. Immune system in suicide-gene therapy. Lancet 1997;349:2-3.

15 Cavallo F, Signorelli P, Giovarelli M, et al Antitumo efficacy of adenocarcinoma cells engineered to produce interleukin 12 (IL-12) or other cytokines compared with exogenous IL-12. F Natl Cancer Inst 1997;89:1049-58.

16 Zitvogel L, Tahara $\mathrm{H}$, Robbins $\mathrm{PD}$, et al. Cance immunotherapy of established tumors with IL-12. F Immunol 1995;155:1393-403.

17 Bramson JL, Hitt M, Addison CL, et al. Direct intratumoral injection of an adenovirus expressing interleukin-12 induces regression and long-lasting immunity that is associated with highly localized expression of interleukin-12. Hum Gen Ther 1996; 7:1995-2002.

18 Brunda MJ, Luistro L, Warrier RR, et al. Antitumor and antimetastatic activity of interleukin 12 against murine tumors. ₹ Exp Med 1993;178:1223-30.

19 Lode HN, Dreier T, Xiang R, et al. Gene therapy with a single chain interleukin 12 fusion protein induces $T$ cell-dependent protective immunity in a syngeneic model of murine neuroblastoma. Proc Natl Acad Sci USA of murine neuro

20 Rakhmilevich AL, Turner J, Ford MJ, et al. Gene gun-mediated skin transfection with interleukin 12 gene results in regression of established primary and metastatic murine tumors. Proc Natl Acad Sci USA 1996; 93:6291-6

21 Tahara H, Zitvogel L, Storkus WJ, et al. Effective eradication of established murine tumors with IL-12 gene therapy using a polycistronic retroviral vector. F Immunol 1995;154 6466-74

22 Qin H, Chatterjee K. Cancer gene therapy using tumor cells infected with recombinant vaccinia virus expressing GM-CSF. Hum Gene Ther 1996;7:1853-60.

23 Yu JS, Burwick JA, Dranoff G, et al. Gene therapy for metastatic brain tumors by vaccination with granulocytemacrophage colony-stimulating factor-transduced tumor cells. Hum Gene Ther 1997;8:1065-72.

24 Lee C-T, Wu S, Ciernik F, et al. Genetic immunotherapy of established tumors with adenovirus-murine granulocyteestablished tumors with adenovirus-murine granulocytemacrophage co

25 Dranoff G, Jaffee E, Lazenby A, et al. Vaccination with irradiated tumor cells engineered to secrete murine granulocyte-macrophage colony-stimulating factor stimulates potent, specific, and long-lasting anti-tumor immunity. Proc Natl Acad Sci USA 1993;90:3539-3543.

26 Cosset F-L, Takeuchi Y, Batttini J-L, et al. High-titer packaging cells producing recombinant retroviruses resistant to human serum. F Virol 1995;69:7430-6.

27 Perrin P, Cassagnau E, Burg C, et al. An interleukin $2 /$ sodium butyrate combination as immunotherapy for rat colon cancer peritoneal carcinomatosis. Gastroenterology 1994;107:1697-708.
28 Barba D, Hardin J, Sadelain M, et al. Development of antitumor immunity following thymidine kinase-mediated kill1994;91:4348-52.

29 Vile RG, Nelson JA, Castleden S, et al. Systemic gene therapy of murine melanoma using tissue specific expression of the HSVtk gene involves an immune system. Cancer Res 1994;54:6228-34

30 Vile RG, Castleden S, Marshall J, et al. Generation of an anti-tumor immune response in a non-immunogenic tumor: HSVtk killing in vivo stimulates a mononuclear cell infiltrate and a TH1-like profile of intratumoral cytokine expression. Int $\mathcal{F}$ Cancer 1997;71:267-74.

31 Felzmann T, Ramsey W, Blaese R. Characterization of the antitumor immune response generated by treatment of murine tumors with recombinant adenoviruses expressing HSVtk, IL-2, IL-6 or B7-1. Gene Ther 1997;4:1322-9.

32 Gagandeep S, Brew R, Green B, et al. Prodrug-activated gene therapy: involvement of an immunological compo-
nent in the "bystander effect". Cancer Gene Ther 1996;3: 83-8.

33 Ramesh R, Marrogi AJ, Munshi A, et al. In vivo analysis of he "bystander effect": a cytokine cascade. Exp Hematol 1996;24:829-38.

34 Bonnekoh B, Greenhalgh DA, Chen S-H, et al. Ex vivo and in vivo adenovirus-mediated gene therapy strategies induce a systemic anti-tumor immune defence in the B16 melanoma model. F Invest Dermatol 1998;110:867-71.

35 Hayashi S, Emi N, Yokoyama I, et al. Inhibition of establishment of hepatic metastasis in mice by combination gene therapy using both herpes simplex virus-thymidine kinase and granulocyte macrophage-colony stimulating factor genes in murine colon cancer. Cancer Gene Ther 1997;4:339-44.

36 Coll J-L, Mesnil M, Lefebvre M-F, et al. Long-term survival of immunocompetent rats with intraperitoneal colon carcinoma tumors using herpes simplex thymidine kinase/ ganciclovir and IL-2 treatments. Gene Ther 1997;4:1160-6.

37 Chen S, Li Chen XH, Wang Y, et al. Combination gene therapy for liver metastasis of colon carcinoma in vivo. Proc Natl Acad Sci USA 1995;92:2577-81.

38 Chen S-H, Kosai K-I, Xu B, et al. Combination suicide and cytokine gene therapy for hepatic metastases of colon carcinoma: sustained antitumor immunity prolongs animal survival. Cancer Res 1996;56:3758-62.

39 Consalvo M, Mullen CA, Modesti A. 5-Fluorocytosine induced eradication of murine adenocarcinomas engineered to express the cytosine deaminase suicide gene requires host immune competence and leaves an efficient memory. F Immunol 1995;154:5302-12.

40 Misawa T, Chiang MH, Pandit L, Gordon EM, Anderson WF, Parekh D. Development of systemic immunologic responses against hepatic metastases during gene therapy for peritoneal carcinomatosis with retroviral Hs-tk and ganciclovir. F Gastrointest Surg 1997;1:527-33. 